\title{
The Effect of Different Attentional Focus on the Penalty Kicking Performance of Adolescent Male Soccer Players in Different Levels
}

\author{
${ }^{1}$ Lixin Zheng * , ${ }^{2}$ Henry Wang \\ ${ }^{1}$ School of Physical Education, Shandong University of Technology, Zibo, China. ${ }^{2}$ Faculty of Applied \\ Health Science, University of Waterloo, Waterloo, Canada.
}

Submitted 02 August 2020; Accepted in final form 17 September 2020.

\begin{abstract}
Background. Previous studies have shown that an external versus the internal focus of attention is an effective and efficient method to improve athletes' performance under anxious conditions. Objectives. The current study aimed to assess the effect of the practice with a distinct focus of attention on the penalty kicking performance of adolescent soccer players with different expertise. Methods. Twenty-four skilled and 24 novice adolescent male soccer players were recruited in the current study. Also, skill-level and age-matched goalkeepers also took part in the study to induce anxiety to the penalty takers. The penalty takers were required to practice penalty kicking toward designated target areas with either an external or internal focus of attention. Results. The results of the mixed analysis of variance (ANOVA) indicated that in the post-test, skilled adolescent soccer players demonstrated superior accuracy with an external versus internal focus $(\mathrm{p}<0.05)$. In contrast, the novices showed greater consistency with an internal than external focus $(\mathrm{p}<0.05)$. Remarkably, the better performance of accuracy in the post-test was not at the cost of kicking velocity $(p>0.05)$. Conclusion. The current study suggests that an appropriate combination of expertise and instruction type (internal vs. external) is critical for improving the penalty kicking performance of adolescent male soccer players.
\end{abstract}

KEYWORDS: Focus of Attention, Soccer, Penalty Kick, Expertise, Keeper-Independent Strategy, Kicking Accuracy, Kicking Consistency.

\section{INTRODUCTION}

The soccer penalty kick is a decisive event that can determine a soccer game $(1,2)$. Especially in the knockout stage, winning or losing of numerous competitions is determined by the penalty shootout. For example, Italy won the 2006 World Cup by defeating France in the penalty shootout. It has been reported that penalty takers have an overwhelming advantage over goalkeepers in the penalty kick because of the stringent spatiotemporal constraints for the goalkeeper (3, 4). Mainly, it takes about 350-500 $\mathrm{ms}$ (5) for the ball to arrive at the goal after being kicked by the penalty taker while the goalkeeper requires at least $600 \mathrm{~ms}$ (6) to dive to the side. Furthermore, it is almost impossible for the goalkeeper to stop the kick, which enters the goal from the top two corners (7).

Notwithstanding the massive advantage in the kicker to score in a penalty kick, the fact is that a large number of penalty kicks are still missed or saved by the goalkeeper $(8,9)$. Converging evidence (10-13) has demonstrated that the penalty kick strategy that the penalty taker adopts also affects the kicking accuracy. Specifically, there are two distinct penalty-taking strategies: keeper-dependent and keeper-independent

*. Corresponding Author:

Lixin Zheng, Professor

E-mail: zhlxsdut@163.com 
strategies $(8,10)$. In the first strategy, the penalty taker anticipates the direction to which the goalkeeper will dive during the run-up and kicks to the opposite side. By contrast, in the keeperindependent strategy, the kicker decides the target location before the run-up and maintains that decision regardless of the goalkeeper's action $(8$, 10). Van der Kamp (10) examined the effect of the penalty kicking strategy on kicking performance. Intermediate level soccer players were recruited to take penalties to the desired target area with either a keeper-dependent or keeper-independent strategy. The results showed that the penalty taker was more accurate when adopting a keeper-independent compared to keeper-dependent strategy while the ball velocity was comparable between the two strategies. Also, kicking accuracy with the keeper-dependent strategy reduced with the decrease of the available time before football contact. Thus, the author (10) suggested that the penalty taker adopt a keeper-independent strategy in the penalty kick.

Even though a recent study (12) has reported that the majority of the penalty takers (i.e., 80\%) adopt a keeper-independent strategy in competition as suggested by the researchers (10, 11), this strategy is not without a flaw: the mere presence of a goalkeeper jeopardizes the penalty kicking accuracy when kickers adopt the keeperindependent strategy $(14,15)$. In particular, with the presence of the goalkeeper, especially when the goalkeeper waves his or her arms during the run-up of the penalty taker (16), the kicker shoots closer to the center of the goal and misses more kicks compared to when the goalkeeper is absent $(14,15)$. According to the attentional control theory (16), the presence of the goalkeeper increases the perceived "threat" and anxiety of the penalty taker (17). It distracts the performer's attention by shifting it from the task-relevant (i.e., the target) stimulus to the task-irrelevant stimulus (i.e., the goalkeeper, 17). This shift requires additional cognitive resources, which may result in the overload of total attentional capacity and consequently deteriorates kicking accuracy (18).

Therefore, it is critical to improving the kicking accuracy of the penalty taker when facing a goalkeeper. In the past two decades, converging evidence has demonstrated the advantage of an external (i.e., directed at movement effects) over the internal focus of attention (i.e., directed at body movements) in improving the spatial accuracy of far aiming tasks $(19,20)$, for example, in golf putting (21), dart-throwing (22), and basketball free-throw shooting (23). Grounded to the constrained action hypothesis (24), an external focus is supposed to promote the automatic control process and improve the effectiveness and efficiency of movements, whereas an internal focus constrains the motor system and consequently interfere with the automatic process. More crucially and relevant to the challenge of anxiety in the penalty kick, attentional capacity demands are reduced with an external compared to an internal focus of attention (24). The total attentional capacity is then less likely to become overloaded with an external focus. For example, Bell and Hardy (25) reported that golfers exhibited more accurate chip shots under anxious conditions when adopting an external than an internal focus of attention. Thus, practicing with an external focus of attention could be a convincing fashion to improve kicking accuracy when facing a goalkeeper.

Recent work by Makaruk et al. $(26,27)$ has investigated the effect of attentional focus on the penalty kicking accuracy. As predicted, participants demonstrate more significant improvement in the penalty kicking accuracy, both with and without the goalkeeper, when adopting an external instead of an internal focus of attention. However, there were several defects in these experiments. First, the researchers (26, 27) only assessed the penalty kicking performance after practice, but overlooked participants' performance before practice. Therefore, the different kicking accuracy between the external and internal groups in the post-test maybe by the group difference before practice.

Moreover, the authors $(26,27)$ only measured kicking accuracy while overlooking kicking velocity. According to Fitts law (28), the penalty taker may sacrifice kicking accuracy for kicking velocity $(29,30)$. It is unclear whether participants decrease kicking velocity to gain kicking accuracy in these experiments $(26,27)$. In addition to these defects, it is still inconclusive whether novice participants benefit from an external focus of attention in the same manner as skilled participants (31-33).

In sum, no existing study has examined whether skilled penalty kickers who adopt an external focus increase their kicking accuracy at the expense of the kicking velocity nor has confirmed that novice soccer players benefit more from an external than internal focus in the penalty 
kick. To this end, both skilled and novice male soccer players were recruited to practice penalty kicks with either an internal or external focus of attention. Before and after practice, both penalty kicking accuracy and velocity were calculated for each participant. It was hypothesized that skilled soccer players would demonstrate better performance after practice with an external focus. At the same time, novices would perform better with an internal focus as they had not achieved the automaticity of movements (34).

\section{MATERIALS AND METHODS}

Participant. Twenty-four skilled (Age $16.3 \pm$ 1.1 years old, soccer experience $8.1 \pm 1.6$ years, range $=6-10$ years) and 24 novice (Age 16.5 \pm 1.2 years old, soccer experience $2.5 \pm 1.1$ years, range $=1-4$ years) adolescent male soccer player volunteered to take part in the experiment. In addition, three skill-level and age-matched goalkeepers for each group were recruited in the experiment. The skilled soccer players and goalkeepers were trained soccer for at least 2 hours, 5 to 7 times per week, whereas the novices played soccer for less than two hours every week. The Ethics Committee approved all procedures of the local University (\#2019142). Before testing, all participants signed a consent form.

Apparatus. Participants executed penalty kicks on an outdoor pitch with artificial grass, a standard soccer goal $(7.32 \times 2.44 \mathrm{~m})$, and a regular size five ball. As illustrated in Figure 1, two PVC canvases with a width of $1.8 \mathrm{~m}$ and a height of $1.2 \mathrm{~m}$ were attached between the crossbar and goalpost. The center of each canvas was a black circle with a diameter of $22 \mathrm{~cm}$, which served as the target. The location of these two targets was chosen because the majority of the penalty kicks toward these areas scored (35). Two cameras (Panasonic, HC-PV100GK) were used to record kickers' performance at a frequency of 50 $\mathrm{Hz}$. One camera was placed about $1 \mathrm{~m}$ to the side of the penalty spot facing the goal line. The other camera was located $5 \mathrm{~m}$ from the goalpost and perpendicular to the goal line (Figure 1).

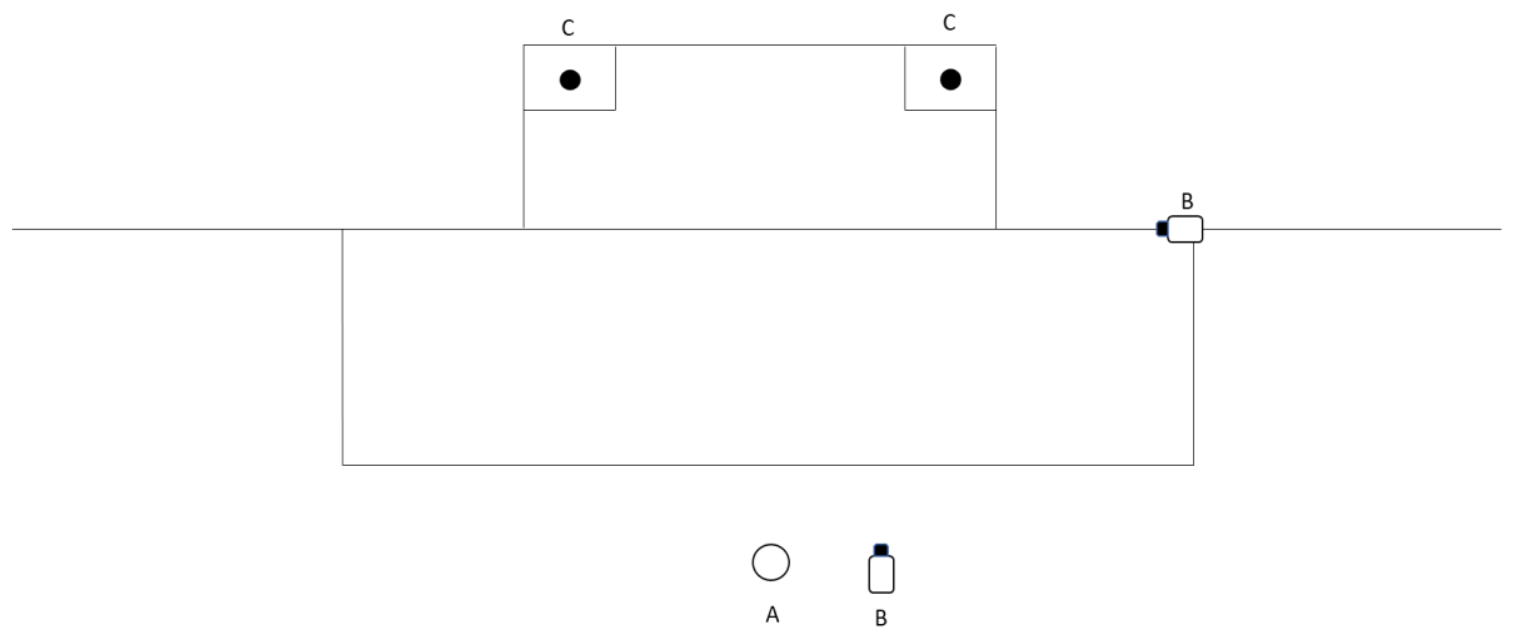

Figure 1. Birds Eye View of Experimental Setups. A: Penalty Kick Spot, B: High-Speed Camera, C: PVC Canvas (1.8 x $1.2 \mathrm{~m})$ with a Black Circle $(22 \mathrm{~cm}$ in diameter) in the Center

Procedure. Both skilled and novice players were randomly assigned to either the external or internal focus of the attention group. Correspondingly, the current study encompassed four groups: skilled-internal focus, skilledexternal focus, novice-internal focus, and novice-external focus. As mentioned before, all participants were required to adopt a keeperindependent strategy and kick toward the center of the canvas (i.e., black circle) as accurately as possible and with enough power. The instructions for internal and external groups were adapted from previous studies $(24,36)$ and listed in Table 1.

The current study consisted of a pre-test, a practice, and a post-test phase. Before all phases, participants performed warm-ups during which they took eight penalty kicks to an empty goal. During the pre-test phase, all participants executed ten penalty kicks to each target with the presence of the goalkeeper, for a total of 20 kicks. In this phase, all kickers have informed the 
designated target before the run-up and to kick toward this target irrespective of the goalkeeper's action. In contrast, goalkeepers were required to save the penalties as they would typically do.

Table 1. Instructions for the External (Left) and Internal (Right) Focus of Attention Group

\begin{tabular}{|c|c|}
\hline External-Focus Instructions & Internal-Focus Instructions \\
\hline 1.Make sure to extend the foot like that of a ballerina & 1. Make sure to point the foot downwards and locked \\
\hline $\begin{array}{l}\text { 2.Make sure to strike the ball just below the midline to lift } \\
\text { it }\end{array}$ & $\begin{array}{l}\text { 2. Make sure to place the foot below the ball's midline to lift } \\
\text { it }\end{array}$ \\
\hline 3.Make sure to strike the ball with laces of the shoe & 3. Make sure to strike the ball with the instep of the foot \\
\hline $\begin{array}{l}\text { 4.Make sure to make a pendulum-like movement before } \\
\text { striking the ball }\end{array}$ & $\begin{array}{l}\text { 4. Make sure to swing the kicking leg backward sufficiently } \\
\text { before striking the ball }\end{array}$ \\
\hline
\end{tabular}

The practice phase consisted of three sessions taking place over three consecutive days. Each session was divided into two blocks of 30 penalty kicks with a break of 10 mins. Participants were required to take penalties toward one designated target in one block and toward another target in the other block. The order of the designated target location was counterbalanced across participants. Also, participants in the external and internal group received instructions from varsity soccer players at the beginning and after every $5^{\text {th }}$ shot. One day after the practice phase, the participant performed the post-test in which they took ten penalties for each target with the presence of the goalkeeper, giving a total of 20 shots. As in the pre-test, all participants were only instructed the desired target location, and goalkeepers were instructed to save the penalties as usual. No instructions about the focus of attention were provided to any group in the post-test.

Data Analysis. Data were derived from the high-speed video recordings $(50 \mathrm{~Hz})$ and analyzed frame by frame using Kinovea software. First, each penalty kick was classified into one of four categories: a hit (i.e., the ball hit on the canvas), a miss (i.e., the ball was shot outside the canvas area, but still within the goalmouth), a failure (i.e., the ball was shot outside the goalmouth) or a block (i.e., the goalkeeper touched the ball). The number of hits, misses, failures, and blocks was counted for each participant. The misses were then excluded from the analysis (15). The final ball position was determined by the moment that the ball crossed the goal line or was touched by the goalkeeper. Kicking accuracy was defined as the distance between the final ball position and the center of the target. Kicking consistency was defined as the standard deviation of the final ball position. Ball flight time was used as a proxy for kicking velocity (15) and was defined as time from the moment of foot-ball contact to the moment the ball crossed the goal line or was touched by the goalkeeper.

All dependent variables were submitted to a 2 level (skilled, novice) by 2 phases (pre-test, posttest) by two instruction (internal focus, external focus) mixed analysis of variance (ANOVA) with repeated measures on the last two factors. For all ANOVAs, the effect size was estimated by partial eta squared $\left(\eta_{\mathrm{p}}{ }^{2}\right)$ with values of 0.01 (small), 0.06 (medium), and 0.14 (large) (37). Alpha level was set at 0.05 , and Tukey's HSD post hoc procedure was used for main effects with more than two means.

\section{RESULTS}

Performance. As shown in Table 2, the ANOVA on hits showed main effects for phase, $\mathrm{F}_{(1,22)}=11.44, \mathrm{p}=0.003, \eta_{\mathrm{p}}{ }^{2}=0.34$, and level, $\mathrm{F}_{(1 \text {, }}$ ${ }_{22}=57.33, \mathrm{p}<0.001, \eta_{\mathrm{p}}{ }^{2}=0.72$. Overall, participants hit the canvas more frequently in the post-test than the pre-test. The main effect for level revealed that skilled soccer players hit the canvas more times than the novices. Moreover, a significant focus by phase by level interaction was discerned, $F_{(1}$, 22) $=7.96, \mathrm{p}<0.01, \eta_{\mathrm{p}}{ }^{2}=0.27$. Post hoc analyses indicated that skilled players who adopted an external focus of attention increased the number of hits after practice and hit the canvas more times than those who adopted an internal focus of attention in the post-test (Table 2).

The analysis of misses revealed a main effect for level, $\mathrm{F}_{(1,22)}=11.47, \mathrm{p}=0.003, \eta_{\mathrm{p}}{ }^{2}=0.34$, and $\mathrm{a}$ significant focus by phase by level interaction, $\mathrm{F}_{(1}$, 22) $=5.04, \mathrm{p}=0.035, \eta_{\mathrm{p}}^{2}=0.19$. Novices had more shots out of the canvas area but still within the goalmouth than skilled players. Similar to the results of hits, post hoc analysis of the interaction revealed that skilled soccer players with an external focus decreased the number of misses after practice and missed the target less frequently than those with an internal focus in the post-test (Table 2). 
The ANOVAs on failures only showed a main effect for level, $F_{(1,22)}=37.22, p<0.001, \eta_{p}{ }^{2}=0.63$. Not surprisingly, novices kicked the ball out of the goalmouth more frequently than skilled players (Table 2). Last, the ANOVA on blocks yielded no main effects or significant interactions, all ps $>0.05$.

Table 2. Means and Standard Deviation for Hits, Misses, Failures, and Blocks as a Function of Level, Phase, and Instruction

\begin{tabular}{ccccc}
\hline & \multicolumn{3}{c}{ Pre } & \multicolumn{2}{c}{ Post } \\
\cline { 2 - 5 } Hits & Internal Focus & External Focus & Internal Focus & External Focus \\
Skilled & $8.83(1.99),(000)$ & $8.92(1.83)$ & $9.5(1.45)$ & $11.17(1.70)$ \\
Novice & $6.25(1.48)$ & $6.0(1.41)$ & $6.92(1.51)$ & $6.08(1.73)$ \\
Misses & & & & \\
$\quad$ Skilled & $4(1.21)$ & $3.83(1.40)$ & $3.92(1.56)$ & $2.83(1.34)$ \\
$\quad$ Novice & $5.17(1.59)$ & $4.92(1.56)$ & $4.5(1.17)$ & $4.83(1.59)$ \\
Failures & & & & \\
$\quad$ Skilled & $2.75(1.54)$ & $2.67(1.37)$ & $2.33(0.89)$ & $1.92(1.38)$ \\
$\quad$ Novice & $3.83(1.03)$ & $4.12(1.11)$ & $4.12(1.34)$ & $4.25(1.36)$ \\
Blocks & $4.42(1.62)$ & $4.58(1.62)$ & $4.25(1.48)$ & $4(1.35)$ \\
$\quad$ Skilled & $4.75(1.22)$ & $4.92(1.44)$ & $4.42(1.44)$ & $4.83(1.59)$ \\
Novice & & &
\end{tabular}

Accuracy. There were main effects for level, $\mathrm{F}_{(1,}$ $\left.{ }_{22}\right)=15.54 \mathrm{p}=0.001, \eta_{\mathrm{p}}{ }^{2}=0.41$, phase, $\mathrm{F}_{(1,22)}=28.11$, $\mathrm{p}<0.001, \eta_{\mathrm{p}}{ }^{2}=0.56$, as well as a significant focus by phase by level interaction, $\mathrm{F}_{(1,22)}=4.86, \mathrm{p}=0.038$, $\eta_{\mathrm{p}}{ }^{2}=0.18$.

As illustrated in Figure 2, a skilled soccer player has demonstrated greater accuracy compared to the novices. Post hoc analysis of the interaction revealed skilled soccer players with an external focus showed enhanced the kicking accuracy after practice and were more accurate than those with an internal focus in the post-test.
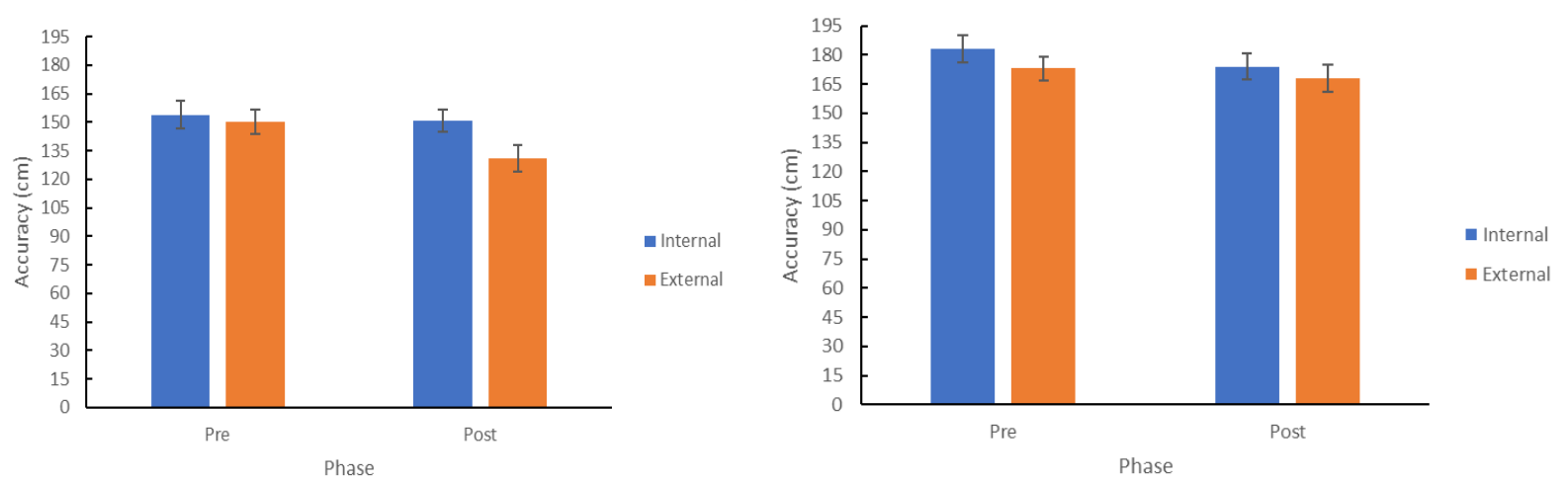

Figure 2. Kicking Accuracy as a Function of Phase and Instruction for Skilled (Left Panel) and Novice (Right Panel) Penalty Takers. Error Bars Represent Standard Error of Mean.

Consistency. The ANOVA on consistency showed main effects for level, $\mathrm{F}(1,22)=81.66$, $\mathrm{P}<0.001, \eta_{\mathrm{p}}{ }^{2}=0.79$, phase, $\mathrm{F}(1,22)=18.57, \mathrm{P}$ $<0.001, \eta_{\mathrm{p}}{ }^{2}=0.46$, and a significant focus by phase by level interaction, $\mathrm{F}(1,22)=23.99, \mathrm{P}<$ $0.001, \eta_{\mathrm{p}}{ }^{2}=0.52$. Again, the variability of the penalty kicks was smaller in the high skilled players than the novices. Post hoc analysis of the interaction indicated that skilled soccer players with an external focus had a smaller variable error in the post-test than pre-test and were less variable than those with an internal focus in the post-test. On the contrary, novice soccer players with an internal focus demonstrated more consistent shots after practice and were more consistent than the novices with an external focus (Figure 3).

Ball Flight Time. As illustrated in Figure 4, no significant effects or interactions were yields on the analysis of ball flight time, all ps $>0.05$. 

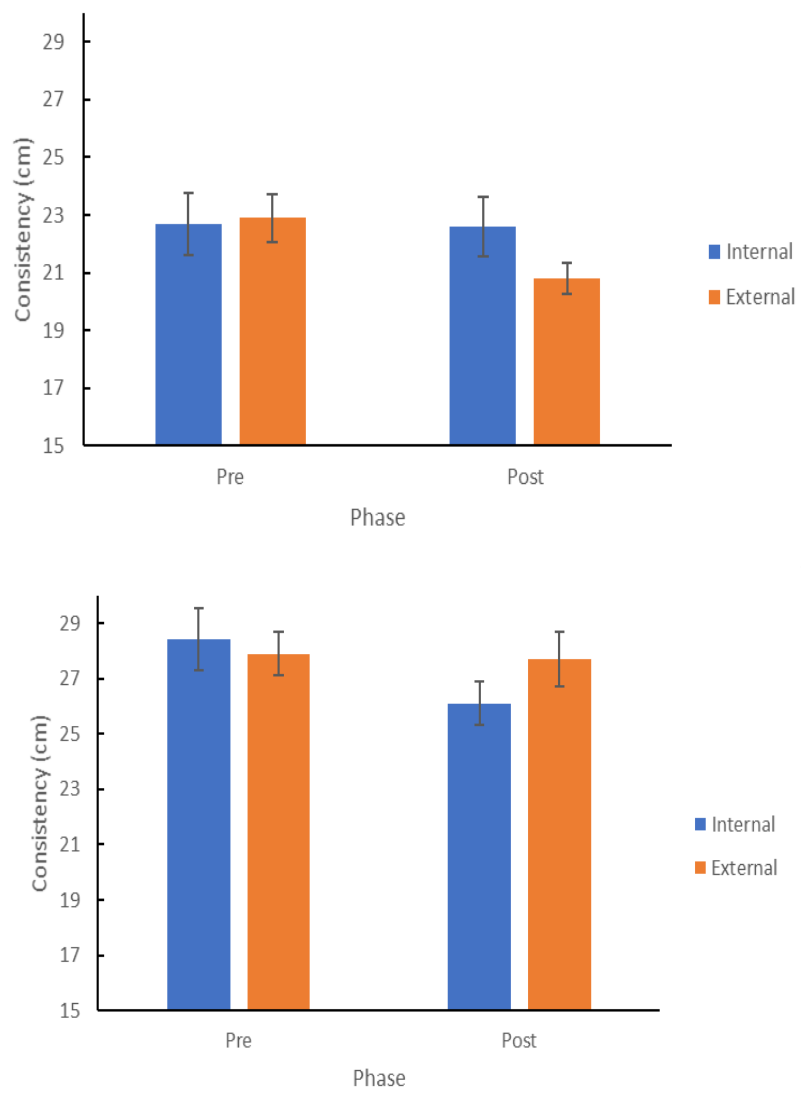

Figure 3. Kicking Consistency as a Function of Phase and Instruction for Skilled (Left Panel) and Novice (Right Panel) Penalty Takers. Error Bars Represent Standard Error of Mean.
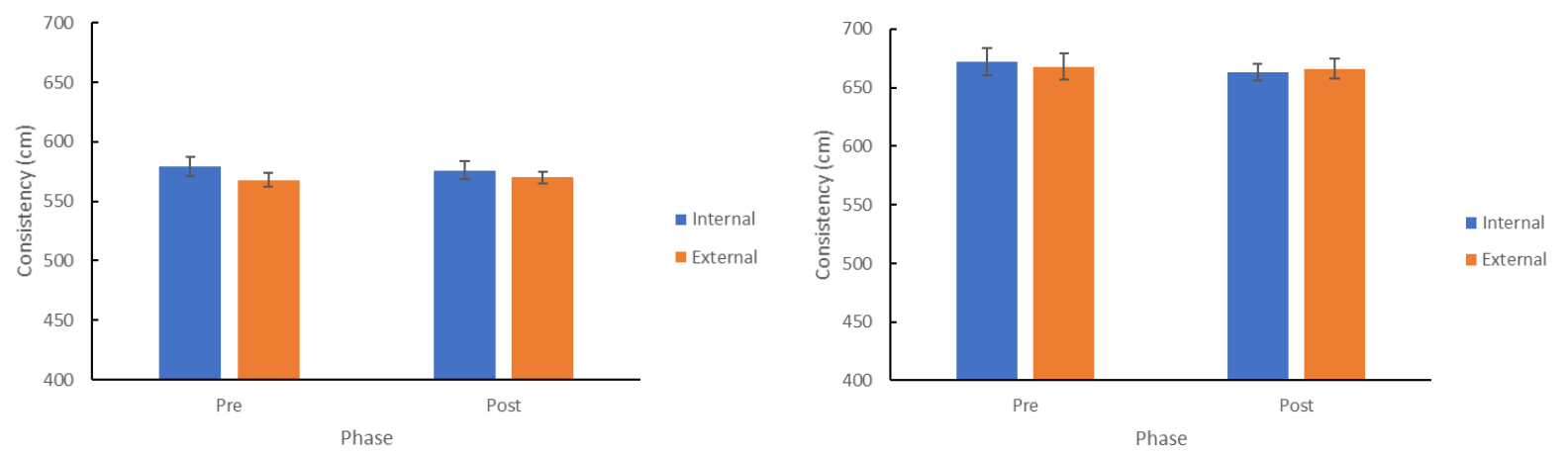

Figure 4. Ball Flight Time as a Function of Phase and Instruction for Skilled (Left Panel) and Novice (Right Panel) Penalty Takers. Error Bars Represent Standard Error of Mean.

\section{DISCUSSION}

The current study aimed to examine how the practice with a distinct focus of attention affected the penalty kicking performance of adolescent soccer players in different levels under anxious conditions (i.e., with the presence of goalkeepers). To this end, both skilled and novice adolescent soccer players were recruited and randomly assigned to either an external or internal focus group to practice penalty kicking. We hypothesized that under anxious conditions, soccer players of distinct levels would benefit from the different focus of attention due to their movement automaticity (34). Consistent with our hypothesis, the results indicated that skilled adolescent soccer players demonstrated superior performance with an external focus. In 
contrast, the performance of adolescent novices was better with an internal focus of attention.

In line with previous findings $(25,38)$, our results suggested that skilled adolescent soccer players performed better with an external compared to an internal focus of attention when facing a goalkeeper. Based on the constrained action hypothesis (24), adopting an external focus promotes the automaticity of the movement and reduces the attentional capacity demands for the current task. For example, Wulf, McNevin, and Shea (24) measured the reaction times of participants balancing on a stabilometer with either an external or internal focus. The researchers (24) found that participants with an external focus showed shorter reaction times in this dual task setup. Thus, under anxious conditions in which the task-irrelevant stimuli compete with task-relevant stimuli for limited cognitive resources, the total attentional capacity is less likely to be overloaded with an external compared to an internal focus. Also, an external focus of attention could prevent participants from paying too much attention to the task-irrelevant stimuli (i.e., the goalkeeper) and help participants concentrate on the task-relevant stimuli (i.e., the target) (27).

On the contrary, an internal focus of attention leads to the participants developing an explicit knowledge of the skill (39). In anxious conditions (e.g., facing a goalkeeper), the explicit knowledge not only occupies the storage space of cognitive resources but also disrupts the automatic control process by involving in the conscious control (40, 41). In the current study, the instructions about kicking actions (i.e., an internal focus) employed the space of cognitive resources, which possibly led to the excess of total attentional capacity. Therefore, it was observed that skilled adolescent players had more accurate and consistent kicks when adopting an external versus the internal focus of attention.

There is debate regarding whether they have superior performance with an external compared to an internal focus of attention (19, 31-34). Results from the current study seem to support that a focus on the movement itself is more beneficial for novice adolescent soccer players. According to the de-automaticity of skill hypothesis (31), less-skilled players have not established the automaticity of skill, nor developed a strong connection between an action and its effect $(41,42)$. Contrary to skilled participants, novice participants can profit from the instructions that direct attention to body parts (i.e., an internal focus), yet not benefit from conditions that direct attention to movement effect (i.e., an external focus, 31). Moreover, the performance of novice players is less likely to be affected by anxiety and stress compared to skilled players, as novices have not developed explicit rules of the skill, which may obstruct the automatic process under anxious conditions (3840). Combining the non-automaticity of the skill and the small effect of anxious on performance, novice adolescent players demonstrated superior kicking accuracy with an internal instead of an external focus of attention.

In discrete tasks like the soccer kicking (43) and dart throwing (44), it has been suggested that superior performance is strongly associated with the fixation time on the target (i.e., quiet eye) (45). In particular, longer fixation time results in more accurate performance (45). High skilled and more accurate performers show longer quiet eye duration than the low skilled and less accurate ones, respectively (46). Regarding studies about quiet eye duration and the focus of attention, two groups of researchers $(44,47)$ have reported that novice performers who adopted an internal focus of attention demonstrated longer quiet eye periods than those who adopted an external focus of attention. As a result, the longer duration of the quiet eye may be another factor which leads to the better performance in adolescent novice soccer player with an internal than external focus.

One limitation of this study was that no gain on kicking velocity was revealed after practice. First, in the current study, participants were only aware of the discrepancy between the center of the target and the ball hit. However, they did not know how fast they kicked. Consequently, participants only received visual feedback of their kicking accuracy while they did not have explicit knowledge of their kicking velocities. The visual feedback of kicking accuracy can not only be used for error correction but also increases the participants' motivation for learning (48). On the contrary, the absence of feedback on ball speed might hinder the improvement of kicking velocity.

Also, skilled soccer players had been trained soccer for at least 2 hours almost every day before and during the experimental period. Thus, the current practice load was not strong enough to increase their kicking velocity. According to 
Bernstein's theory of motor learning, the first freeze the degree of freedom (DOF) of movements to simplify the movement control, and then release the DOF to reach the goal by different methods (49). It is possible that novice kickers were still during a phase in which they froze the DOF to achieve a simplified movement. Given that a high kicking velocity is usually associated with the freeing of movement (30), we only observed an improvement in the kicking accuracy, but not in the kicking velocity. Thus, future research may provide the soccer players with the feedback of ball speed (e.g., using a radar gun) and sufficient training load to examine if they could increase kicking velocity after practice with a different focus of attention.

\section{CONCLUSION}

In sum, the results of the current study were by previous findings that are focusing on the movement effect is an effective method to improve the kicking accuracy of skilled adolescent soccer players under anxious conditions. Also, we found that novice adolescent soccer players showed superior kicking performance with an internal versus external focus of attention under anxious conditions. Notably, more accurate performance in both skilled players with an external focus and novice players with an internal focus was not at the expense of kicking velocity. We thus suggest that coaches should consider the level of the player when instructing them to perform penalty kicking.

\section{APPLICABLE REMARKS}

- Both skilled and novice soccer players can improve their penalty kicking performance after practice. However, an external focus of attention leads to higher kicking accuracy for skilled players, while an internal focus of attention results in greater kicking consistency for the novice.

\section{REFRENCES}

1. Bar-Eli M, Azar H, Ritov I, Keidar-Levin Y, Schein G. Action bias among elite soccer goalkeepers: the case of penalty kicks. J Econ Psychol. 2007;28(5):606-621. doi: 10.1016/j.joep.2006.12.001

2. Paterson G, Kamp JV, Savelsbergh G. Moving Advertisements Systematically Affect Gaze Behavior and Performance in the Soccer Penalty Kick. Front Sports Act Living. 2020;1:69. doi: 10.3389/fspor.2019.00069

3. Van der Kamp J, Dicks M, Navia JA, Noël B. Goalkeeping in the soccer penalty kick. German J Exercise Sport Res. 2018;48(2):169-175. doi: 10.1007/s12662-018-0506-3

4. Memmert D, Hüttermann S, N. H, Loffing F, Strauss B. Dueling in the penalty box: evidence-based recommendations on how shooters and goalkeepers can win penalty shootouts in soccer. Int Rev Sport Exercise Psychol. 2013;6(1):209-229. doi: 10.1080/1750984X.2013.811533

5. Morya E, Bigatão H, Lees A, Ranvaud R, Cabri J, Araújo D. Evolving penalty kick strategies: World cup and club matches 2000-2002. Sci Football V. 2005;27:241-247.

6. Franks IM, Harvey I. Cues for Goalkeepers-High-tech methods used to measure penalty shot response. Soc J. 1997;42:30-38.

7. Bar-Eli M, Azar OH. Penalty kicks in soccer: an empirical analysis of shooting strategies and goalkeepers' preferences. Socc Soc. 2009;10(2):183-191. doi: 10.1080/14660970802601654

8. Kuhn W. Penalty-Kick Strategies for Shooters and Goalkeepers, in: Reilly, T., Lees, A., Davids, K. and Murphy, W.J., eds., Science and Football I. London: E \& FN Spon, UK; 1988.

9. Navia JA, Van der Kamp JO, Ruiz LM. On the use of situational and body information in goalkeeper actions during a soccer penalty kick. Int J Sport Psychol. 2013;44(3):234-251.

10.van der Kamp J. A field simulation study of the effectiveness of penalty kick strategies in soccer: late alterations of kick direction increase errors and reduce accuracy. J Sports Sci. 2006;24(5):467-477. doi: 10.1080/02640410500190841 pmid: 16608761

11.van der Kamp J. Exploring the merits of perceptual anticipation in the soccer penalty kick. Motor Control. 2011;15(3):342-358. doi: 10.1123/mcj.15.3.342 pmid: 21878688

12. Noel B, Furley P, van der Kamp J, Dicks M, Memmert D. The development of a method for identifying penalty kick strategies in association football. $J$ Sports Sci. 2015;33(1):1-10. doi: 10.1080/02640414.2014.926383 pmid: 24914924 
13. Navarro M, van der Kamp J, Schor P, Savelsbergh GJP. Implicit learning increases shot accuracy of football players when making strategic decisions during penalty kicking. Hum Mov Sci. 2018;61:72-80. doi: 10.1016/j.humov.2018.07.004 pmid: 30031272

14. Wood G, Wilson MR. Gaze behaviour and shooting strategies in football penalty kicks: Implications of a 'keeper-dependent approach. Int J Sport Psychol. 2010;41(3):293-312.

15. Navarro M, van der Kamp J, Ranvaud R, Savelsbergh GJ. The mere presence of a goalkeeper affects the accuracy of penalty kicks. J Sports Sci. 2013;31(9):921-929. doi: 10.1080/02640414.2012.762602 pmid: 23360203

16. Wood G, Wilson MR. A moving goalkeeper distracts penalty takers and impairs shooting accuracy. $J$ Sports Sci. 2010;28(9):937-946. doi: 10.1080/02640414.2010.495995 pmid: 20568032

17. Bar-Haim Y, Lamy D, Pergamin L, Bakermans-Kranenburg MJ, van IMH. Threat-related attentional bias in anxious and nonanxious individuals: a meta-analytic study. Psychol Bull. 2007;133(1):1-24. doi: 10.1037/0033-2909.133.1.1 pmid: 17201568

18. Mullen R, Hardy L, Tattersall A. The effects of anxiety on motor performance: A test of the conscious processing hypothesis. J Sport Exercise Psy. 2005;27(2):212-225. doi: 10.1123/jsep.27.2.212

19. Wulf G. Attentional focus and motor learning: a review of 15 years. Int Rev Sport Exercise Psychol. 2013;6(1):77-104. doi: 10.1080/1750984X.2012.723728

20. Wulf G, Lewthwaite R. Optimizing performance through intrinsic motivation and attention for learning: The OPTIMAL theory of motor learning. Psychon Bull Rev. 2016;23(5):1382-1414. doi: 10.3758/s13423-015-0999-9 pmid: 26833314

21. Wulf G, Su J. An external focus of attention enhances golf shot accuracy in beginners and experts. Res Q Exerc Sport. 2007;78(4):384-389. doi: 10.1080/02701367.2007.10599436 pmid: 17941543

22.Lohse KR, Sherwood DE, Healy AF. How changing the focus of attention affects performance, kinematics, and electromyography in dart throwing. Hum Mov Sci. 2010;29(4):542-555. doi: 10.1016/j.humov.2010.05.001 pmid: 20541275

23.Zachry T, Wulf G, Mercer J, Bezodis N. Increased movement accuracy and reduced EMG activity as the result of adopting an external focus of attention. Brain Res Bull. 2005;67(4):304-309. doi: 10.1016/j.brainresbull.2005.06.035 pmid: 16182938

24. Wulf G, McNevin N, Shea CH. The automaticity of complex motor skill learning as a function of attentional focus. $Q J$ Exp Psychol A. 2001;54(4):1143-1154. doi: 10.1080/713756012 pmid: 11765737

25.Bell JJ, Hardy J. Effects of Attentional Focus on Skilled Performance in Golf. J Appl Sport Psychol. 2009;21(2):163-177. doi: 10.1080/10413200902795323

26. Makaruk H, Porter JM, Sadowski J, Bodasinska A, Zielinski J, Niznikowski T, et al. The effects of combining focus of attention and autonomy support on shot accuracy in the penalty kick. PLoS One. 2019;14(9):e0213487. doi: 10.1371/journal.pone.0213487 pmid: 31545800

27. Makaruk H, Porter JM, Bodasinska A, Palmer S. Optimizing the penalty kick under external focus of attention and autonomy support instructions. Eur J Sport Sci. 2020:1-9. doi: 10.1080/17461391.2020.1720829 pmid: 31983301

28. Fitts PM. The information capacity of the human motor system in controlling the amplitude of movement. J Exp Psychol. 1954;47(6):381-391. pmid: 13174710

29. van den Tillaar R, Ulvik A. Influence of instruction on velocity and accuracy in soccer kicking of experienced soccer players. J Mot Behav. 2014;46(5):287-291. doi: 10.1080/00222895.2014.898609 pmid: 24773185

30.van den Tillaar R, Fuglstad P. Effect of Instructions Prioritizing Speed or Accuracy on Kinematics and Kicking Performance in Football Players. J Mot Behav. 2017;49(4):414-421. doi: 10.1080/00222895.2016.1219311 pmid: 27740895

31.Perkins-Ceccato N, Passmore SR, Lee TD. Effects of focus of attention depend on golfers' skill. J Sports Sci. 2003;21(8):593-600. doi: 10.1080/0264041031000101980 pmid: 12875310

32. Castaneda B, Gray R. Effects of focus of attention on baseball batting performance in players of differing skill levels. J Sport Exerc Psychol. 2007;29(1):60-77. doi: 10.1123/jsep.29.1.60 pmid: 17556776

33. Ford P, Hodges NJ, Williams AM. Online attentional-focus manipulations in a soccer-dribbling task: implications for the proceduralization of motor skills. J Mot Behav. 2005;37(5):386-394. doi: 10.3200/JMBR.37.5.386-394 pmid: 16120565 
34. Beilock SL, Wierenga SA, Carr TH. Expertise, attention, and memory in sensorimotor skill execution: impact of novel task constraints on dual-task performance and episodic memory. $Q J$ Exp Psychol A. 2002;55(4):1211-1240. doi: 10.1080/02724980244000170 pmid: 12420993

35. Almeida CH, Volossovitch A, Duarte R. Penalty kick outcomes in UEFA club competitions (20102015): The roles of situational, individual and performance factors. Int J Performance Anal Sport. 2017;16(2):508-522. doi: 10.1080/24748668.2016.11868905

36. Schwab S, Rein R, Memmert D. "Kick it like Ronaldo": a cross-sectional study of focus of attention effects during learning of a soccer knuckle ball free kick technique. German J Exercise Sport Res. 2018;49(1):91-96. doi: 10.1007/s12662-018-0558-4

37. Cohen J. A power primer. Psychol Bull. 1992;112(1):155-159. doi: 10.1037//0033-2909.112.1.155 pmid: 19565683

38. Lawrence GP, Virian J, Oliver SJ, Gottwald VM. Lets go surfing now, everybody's learning how; attentional strategies on expert and novice surfing performance under both practice and competition conditions. Eur J Sport Sci. 2020;20(2):229-239. doi: 10.1080/17461391.2019.1626489 pmid: 31148515

39. Hardy L, Mullen R, Martin N. Effect of task-relevant cues and state anxiety on motor performance. Percept Mot Skills. 2001;92(3 Pt 1):943-946. doi: 10.2466/pms.2001.92.3.943 pmid: 11453229

40. Masters R, Maxwell J. The theory of reinvestment. Int Rev Sport Exercise Psychol. 2008;1(2):160-183. doi: 10.1080/17509840802287218

41.Bernstein NA. Dexterity and its development. In On Dexterity and its Development (edited and translated by M.L. Latash and M.T. Turvey). Mahwah: NJ: Lawrence Erlbaum; 1996.

42. Ford P, Hodges NJ, Mark Williams A. An evaluation of end-point trajectory planning during skilled kicking. Motor Control. 2009;13(1):1-24. doi: 10.1123/mcj.13.1.1 pmid: 19246775

43.Piras A, Vickers JN. The effect of fixation transitions on quiet eye duration and performance in the soccer penalty kick: instep versus inside kicks. Cogn Process. 2011;12(3):245-255. doi: 10.1007/s10339-0110406-z pmid: 21544570

44. Querfurth S, Schucker L, de Lussanet MH, Zentgraf K. An Internal Focus Leads to Longer Quiet Eye Durations in Novice Dart Players. Front Psychol. 2016;7:633. doi: 10.3389/fpsyg.2016.00633 pmid: 27199860

45. Vickers JN. Advances in coupling perception and action: the quiet eye as a bidirectional link between gaze, attention, and action. Prog Brain Res. 2009;174:279-288. doi: 10.1016/S0079-6123(09)01322-3

46. Mann DT, Williams AM, Ward P, Janelle CM. Perceptual-cognitive expertise in sport: a meta-analysis. J Sport Exerc Psychol. 2007;29(4):457-478. doi: 10.1123/jsep.29.4.457 pmid: 17968048

47. Rienhoff R, Fischer L, Strauss B, Baker J, Schorer J. Focus of attention influences quiet-eye behavior: An exploratory investigation of different skill levels in female basketball players. Sport Exercise Perform Psychol. 2015;4(1):62-74. doi: 10.1037/spy0000031

48. Schmidt RA, Lee TD, Winstein C, Wulf G, Zelaznik HN. Motor control and learning: A behavioral emphasis. Human kinetics, IL, USA2018.

49. Guimaraes AN, Ugrinowitsch H, Dascal JB, Porto AB, Okazaki VHA. Freezing Degrees of Freedom During Motor Learning: A Systematic Review. Motor Control. 2020:1-15. doi: 10.1123/mc.2019-0060 pmid: 32221040 